\title{
Relevance of minor discrepancies at second pathology review in gynaecological
}

\section{cancer}

\author{
Lucas Minig1,a (D), José Manuel Bosch², Carmen Illueca ${ }^{3}$, Cristina Zorrero², José Miguel Cárdenas-Rebollo ${ }^{4}$, Julia Cruz ${ }^{3}$ and Ignacio Romero \\ ${ }^{1}$ Gynecology Department, CEU Cardenal Herrera University, 46115 Valencia, Spain \\ ${ }^{2}$ Gynecology Department, Instituto Valenciano de Oncología (IVO), 46009 Valencia, Spain \\ ${ }^{3}$ Pathology Department, Instituto Valenciano de Oncología (IVO), 46009 Valencia, Spain \\ ${ }^{4}$ Department of Applied Mathematics and Statistics, CEU San Pablo University, 28003 Madrid, Spain \\ ${ }^{5}$ Medical Oncology Department, Instituto Valenciano de Oncología (IVO), 46009 Valencia, Spain \\ ahttps://orcid.org/0000-0001-7648-5604
}

\section{Abstract}

Aim: To determine the incidence of discrepancy rate between the initial pathology diagnosis and referral diagnosis in women with gynaecological cancer.

Methods: A retrospective observational study was performed including all consecutive patients with gynaecological cancer referred and who underwent pathologic review between January 2013 and May 2017. Discrepancies were minor when future treatment was not altered or major when the treatment was modified.

Results: A total of 259 patients were included. The original diagnosis was ovarian cancer ( $n=126,48.6 \%$ ), endometrial cancer $(n=84,32.4 \%)$, cervical cancer $(n=43,16.6 \%)$ and vulvar cancer $(n=6,2.3 \%)$. Eighteen women (6.9\%) had major discrepancies and 69 patients $(26.6 \%)$ had minor discrepancies. The main reason for the minor discrepancy was tumour grade or histology subtype. Regarding ovarian cancer, 13 out of 16 patients had minor discrepancies at histology subtype among serous, endometrioid, mucinous or undifferentiated tumours. The main issue for the minor discrepancy in patients with cervical cancer was among different subtype of cervical adenocarcinoma. Minor discrepancies due to tumour grade were also observed in 14, 19, 8 and 3 patients with endometrial, ovarian, cervical and vulvar cancer, respectively.

Conclusions: A second pathology review also adds valid information in those cases with minor discrepancies leading to a difference in patients' counselling regarding follow-up and prognosis.

Keywords: second opinion, pathology, diagnosis, gynaecological cancer, referral cancer centres, quality of care

\section{Introduction}

Discrepancy in the pathology diagnosis is possible among different pathologists [1]. In fact, the disagreement seems to be more frequent for gynaecological pathologies [2]. Thus, secondary pathology review for gynaecological cancer is a common practice at referral centres [3]. It is defined as the review of pathology specimens, by a second

Correspondence to: Lucas Minig Email: miniglucas@gmail.com.br

ecancer 2019, 13:929

https://doi.org/10.3332/ecancer.2019.929

Published: 13/05/2019

Received: 16/02/2019

Publication costs for this article were supported by the ecancer Global Foundation.

Copyright: $₫$ the authors; licensee ecancermedicalscience. This is an Open Access article distributed under the terms of the Creative Commons Attribution License (http:// creativecommons.org/licenses/by/3.0), which permits unrestricted use, distribution, and reproduction in any medium, provided the original work is properly cited. 
pathologist, which is usually initiated at the request of the treating clinician, multidisciplinary tumour board, quality control protocol or as standard practice to review all cases at a specialised centre prior to treatment [4]. According to the American Society of Clinical Pathology, pathology review is recommended as an important component of total quality programmes in diagnostic surgical pathology, being a key aspect in the assurance of patient safety for tissue-based diagnoses [5].

Some authors have found that discrepancies between the initial diagnosis of gynaecological cancer and the second opinion leading to modification of the treatment, referred to as a major discrepancy, can range between $0.6 \%$ to $13.5 \%$ of cases [1, 3, 6-11]. However, there is little information in the literature regarding discrepancies that do not modify future treatments but can alter the prognosis of the disease, the patient's counselling, as well as the follow-up. Therefore, this study aims to determine the incidence of discrepancy rate between the initial and referral pathology diagnosis in women with gynaecological cancer.

\section{Materials and methods}

\section{Study design}

A retrospective observational study was performed in all consecutive patients with gynaecological cancer referred to the Instituto Valenciano de Oncología (IVO), in Valencia, Spain. Patients who attended for a second opinion and who underwent pathologic review between January 2013 and May 2017 were included. Patients with non-described information at the initial pathology diagnosis, such as tumour grade or histology subtype, were also included. Patients with insufficient sample to establish a second pathology review were excluded from this study.

\section{Data collection}

Information regarding the original pathology diagnosis was abstracted from the original pathology report and included the type of sample (biopsy or tumour specimen), site of tumour, histology subtype and grade of differentiation. The second pathology diagnosis was collected from the patient's chart and included: site of tumour, histology subtype, the grade of tumour differentiation, as well as the modification on the patient's treatment. The type of discrepancy was classified in accordance with other authors [1, 3, 7, 9] as: minor discrepancy, when it did not impact on future clinical practice (including those patients previously treated or with missing information at the original pathology report); and major discrepancy, when it did modify the patient's future planned treatment.

\section{Pathology examination at IVO}

One pathologist specialising (C.I.) in gynaecological cancer performed the pathology review. In case of any type of discrepancy, a second pathologist (J.C.) reviewed the diagnosis. Both pathologists have more than 20 years of experience in gynaecological cancer. The diagnosis was based on criteria described in textbooks, as well as the WHO Classification of Tumours of Female Reproductive Organs [12, 13]. Additional immunohistochemical stains were performed following institutional protocols to achieve the final pathology diagnosis or as part of specific clinical trials. The information was presented in a weekly multidisciplinary tumour board to establish the appropriate treatment plan.

\section{Literature review}

A literature search in PubMed was performed using the following criteria: ('pathology'[Subheading] OR 'pathology'[All Fields] OR 'pathology' [MeSH Terms]) AND slide [All Fields] AND ('review' [Publication Type] OR 'review literature as topic' [MeSH Terms] OR 'review' [All Fields])) AND (('gynaecology' [MeSH Terms] OR 'gynaecology' [All Fields] OR 'gynaecological' [All Fields]) AND ('neoplasms' [MeSH Terms] OR 'neoplasms'[All Fields] OR 'cancer'[All Fields])) AND ('01/May/1997'[Date - Publication]: '30/November/2017'[Date - Publication]). The searches were limited to 'English' and 'human'. Additional literature was searched through cross-references of the retrieved articles to extract all relevant literature available.

The inclusion criteria were: (A) Cases series or cohort studies; (B) Studies must describe minor and major discrepancy as described above between initial and second opinion diagnosis. All abstracts of the studies obtained were evaluated for eligibility by two of the authors (Lucas Minig and José Manuel Bosch). 


\section{Statistical analysis}

Frequencies and proportions were used as summary statistics for categorical variables. Time interval to the second opinion was compared by using the chi-square test, where $p<0.05$ was considered as significant differences. Statistical analysis was performed using the IBM SPSS version 20.0 programme.

\section{Results}

Pathology review was required in 259 patients with gynaecological cancer who attended the IVO for a second opinion, representing the analysed patients in this study. Almost half of the patients had ovarian cancer ( $n=126,48.6 \%$ ), while 84 patients (32.4\%) had endometrial cancer, 43 (16.6\%) had cervical cancer and six women (2.3\%) had vulvar cancer. The type of sample analysed included: biopsy in 105 patients $(40.5 \%)$, dilatation and curettage (all endometrial cancer) in ten cases (3.8\%), uterus in 40 women (15.4\%), ovary (all ovarian cancer) in 103 patients (39.7\%) and cervical cone (all cervical cancer) in one case (0.4\%). Immunohistochemical analysis was required in 182 women (71\%). Discrepancy among the initial and referral diagnosis was observed in 87 patients (33.5\%); of them, 69 women (26.6\%) had minor discrepancy and 18 patients (6.9\%) had a major discrepancy. Median (range) time interval to obtain the second opinion was 4 (0-38) days, without significant differences among patients with major and minor discrepancies (Table 1).

Table 1. Patients' characteristics.

\begin{tabular}{|l|l|}
\hline \multicolumn{1}{|c|}{ Characteristics } & \multicolumn{1}{c|}{$N=259$} \\
\hline Type of cancer & \\
\hline Ovarian & $126(48.6 \%)$ \\
\hline Endometrial & $84(32.4 \%)$ \\
\hline Cervical & $43(16.6 \%)$ \\
\hline Vulvar & $6(2.3 \%)$ \\
\hline Type of sample analysed & \\
\hline Biopsy & $105(40.5 \%)^{1}$ \\
\hline D\&C (all endometrial cancer) & $10(3.8 \%)$ \\
\hline Uterus & $40(15.4 \%)$ \\
\hline Ovary (all ovarian cancer) & $103(39.7 \%)$ \\
\hline Cervical cone (cervical cancer) & $1(0.4 \%)$ \\
\hline Pathology characteristics & \\
\hline IHQ requirement & $182(71 \%)$ \\
\hline Discrepancy & $87(33.5 \%)$ \\
\hline Minor & $69(26.6 \%)$ \\
\hline Major & $18(6.9 \%)$ \\
\hline Time interval to the second opinion, in days & Median (range) ${ }^{2}$ \\
\hline All patients $(n=259)$ & $4(0-22)$ \\
\hline Minor discrepancy $(n=82)$ & $4(0-22)$ \\
\hline Major discrepancy $(n=10)$ & $4.5(0-14)$ \\
\hline
\end{tabular}

Legends: D\&C: dilatation and curettage; IHQ: Immunohistochemistry requirement ${ }^{1}$ includes 23 cases of ovarian cancer

${ }^{2} p$-value: 0.276 
Table 2. Minor and major discrepancies among different types of gynaecological cancer.

\begin{tabular}{|c|c|c|c|c|c|c|c|c|}
\hline & \multicolumn{2}{|c|}{$\begin{array}{l}\text { Endometrial cancer } \\
\qquad(n=84)\end{array}$} & \multicolumn{2}{|c|}{$\begin{array}{l}\text { Ovarian cancer } \\
\quad(n=126)\end{array}$} & \multicolumn{2}{|c|}{$\begin{array}{l}\text { Cervical cancer } \\
\qquad(n=43)\end{array}$} & \multicolumn{2}{|c|}{$\begin{array}{l}\text { Vulvar cancer } \\
\qquad(n=6)\end{array}$} \\
\hline & $\begin{array}{l}\text { Minor } \\
16(19 \%)\end{array}$ & $\begin{array}{l}\text { Major } \\
7(8.3 \%)\end{array}$ & $\begin{array}{c}\text { Minor } \\
35(27.7 \%)\end{array}$ & $\begin{array}{l}\text { Major } \\
7(5.5 \%)\end{array}$ & $\begin{array}{c}\text { Minor } \\
15(34.8 \%)\end{array}$ & $\begin{array}{l}\text { Major } \\
4(9.3 \%)\end{array}$ & $\begin{array}{l}\text { Minor } \\
3(50 \%)\end{array}$ & $\begin{array}{l}\text { Major } \\
0(0 \%)\end{array}$ \\
\hline \multicolumn{9}{|c|}{ Discrepancy } \\
\hline Grade & $14(87.5 \%)^{a}$ & $1(14.2 \%)$ & $19(54.2 \%)^{b}$ & 0 & $8(53.3 \%)^{c}$ & 0 & 3 (100\%) & 0 \\
\hline Histology & $1(6.2 \%)$ & 0 & 9 (25.7\%) & 6 (85.7\%) & $4(26.6 \%)$ & $1(25 \%)$ & 0 & 0 \\
\hline Both & $1(6.2 \%)$ & $6(85.7 \%)$ & 7 (20\%) & 1 (14.2\%) & $1(6.6 \%)$ & $2(50 \%)$ & 0 & 0 \\
\hline Origin & 0 & 0 & 0 & 1 (14.2\%) & 2 (13.3\%) & $1(25 \%)$ & 0 & 0 \\
\hline $\mathrm{IHQ}$ & 15 (93.7\%) & 5 (71.4\%) & 32 (91.4\%) & $2(28.4 \%)$ & $6(40 \%)$ & 2 (50\%) & 0 & 0 \\
\hline \multicolumn{9}{|c|}{ Sample analysed } \\
\hline Biopsy & $7(43.7 \%)$ & $4(57.1 \%)$ & 6 (17.1\%) & - & 14 (93.4\%) & $4(100 \%)$ & 3 (100\%) & 0 \\
\hline$D \& C$ & $2(12.5 \%)$ & $1(14.2 \%)$ & - & - & - & - & - & - \\
\hline Uterus & $7(43.7 \%)$ & 2 (28.5\%) & - & - & $1(6.6 \%)$ & 0 & - & - \\
\hline Ovary & - & - & 29 (82.8\%) & 7 (100\%) & - & - & - & - \\
\hline
\end{tabular}

Legends: IHQ: Immunohistochemistry requirement; D\&C: dilatation and curettage

References: (a) Nine patients due to missing information at the original pathology report. (b) Sixteen patients due to missing information at the original pathology report. (c) Six patients due to missing information at the original pathology report

Table 2 describes the characteristics of patients with minor and major discrepancies in different types of gynaecological cancer. Among patients with endometrial cancer, minor and major discrepancies were diagnosed in 16 (19\%) and seven patients (8.3\%), respectively. A total of 14 women (87.5\%) had minor discrepancies at tumour grade, one case (6.2\%) at histology subtype and one at both. One patient (14.2\%) had major discrepancies in tumour grade, while the other six cases (85.7\%) were found in histology and tumour grade. Regarding patients with ovarian cancer, 19 out of 35 patients (54.2\%) with minor discrepancies had tumour grade disagreement, nine women had histology discrepancy, while the remaining seven cases had differences at both histology characteristics.

\section{Minor discrepancy by histology}

A total of 23 patients had minor discrepancies in histopathology and they are detailed in Table 3. Among the 16 patients with the ovarian disease, the discrepancy between serous, endometrioid and mucinous histology was noted in nine cases.

\section{Minor discrepancy by grade}

Nineteen patients with ovarian cancer had minor discrepancy by tumour grade only. In 16 cases, the tumour was graded at IVO since this information was not described at the original pathology report; two patients were downgraded from serous high-grade (G2) to serous lowgrade (G1) epithelial ovarian cancer (EOC); while one patient was upgraded from low-grade (G1) to high-grade (G3) EOC.

Minor discrepancies regarding tumour grade in women with endometrial cancer were observed in 14 patients. Tumour grade information was not described in nine pathology reports; while three patients with $\mathrm{G} 1$ endometrioid endometrial cancer were upgraded to $\mathrm{G} 2$ tumours. The last two cases had G3 and G2 tumours, and they were downgraded to G2 and G1, respectively.

Regarding cervical cancer, the tumour was graded at IVO in two out of the eight patients with minor discrepancy by tumour grade. Three patients were downgraded from G3 to G2 or G1, while three cases were upgraded. Finally, tumour grade was established at IVO in two patients with vulvar cancer; while the tumour was upgraded from $\mathrm{G} 1$ to $\mathrm{G} 2$ in one additional patient with vulvar cancer, all affected by squamous cell carcinoma. 
Table 3. Minor discrepancy by histology.

\begin{tabular}{|c|c|c|c|c|}
\hline & Initial histology & Grade & Final histology & Grade \\
\hline \multicolumn{5}{|c|}{ Ovarian cancer } \\
\hline 1 & Squamous & * & Clear cell & * \\
\hline 2 & Serous borderline & N-Ap & Mucinous borderline & N-Ap \\
\hline 3 & Serous EOC & * & Endometrioid EOC & * \\
\hline 4 & Serous EOC & * & Endometrioid EOC & * \\
\hline 5 & Serous EOC & NA & Mucinous EOC & 2 \\
\hline 6 & Serous EOC & NA & Undifferentiated EOC & 3 \\
\hline 7 & Endometrioid EOC & NA & Serous EOC & $H-G$ \\
\hline 8 & Endometrioid EOC & * & Serous EOC & $*$ \\
\hline 9 & Endometrioid EOC & * & Serous EOC & * \\
\hline 10 & Endometrioid EOC & NA & Serous EOC & $\mathrm{H}-\mathrm{G}$ \\
\hline 11 & Endometrioid EOC & * & Serous EOC & * \\
\hline 12 & Endometrioid EOC & * & Undifferentiated EOC & * \\
\hline 13 & Undifferentiated EOC & * & Serous EOC & * \\
\hline 14 & Undifferentiated EOC & * & Serous EOC & * \\
\hline 15 & Neuroendocrine, hypercalcaemic small cell & * & Undifferentiated EOC & * \\
\hline 16 & Neuroendocrine, Large cell & * & Serous EOC & * \\
\hline \multicolumn{5}{|c|}{ Endometrial cancer } \\
\hline 17 & Endometrioid & $*$ & Mucinous & * \\
\hline 18 & Leiomyosarcoma & 3 & Undifferentiated sarcoma & 3 \\
\hline \multicolumn{5}{|c|}{ Cervical cancer } \\
\hline 19 & Endometrioid & * & Adenosquamous & * \\
\hline 20 & ADC serous & * & ADC mucinous & * \\
\hline 21 & ADC & 1 & ADC endometrioid & 2 \\
\hline 22 & Adenosquamous & $*$ & Squamous & * \\
\hline 23 & ADC villoglandular & * & ADC endometrioid & * \\
\hline
\end{tabular}

Legends: EOC: epithelial ovarian cancer; NA: not available; N-Ap: not applicable; H-G: Highgrade. ADC: Adenocarcinoma *: grade concordance

\section{Major discrepancy}

The characteristics of 18 patients with major discrepancies are described in Table 4. Of note, five patients had uterine cancer where the discrepancy was modified from endometrioid to serous or clear cell endometrial cancer. (cases \# 8, 9, 10,11,12) Discrepancy at the origin of the tumour was diagnosed in two cases. One patient had an initial mucinous EOC and was modified at IVO to metastatic gastric cancer (Krukenberg's tumour). The second case, initially diagnosed as urothelial/endometrial carcinoma at a uterine cervical biopsy, was modified to a poorly differentiated (G3) squamous cervical cancer by using additional immunohistochemistry such as: CK20, CK7, WT-1, P53, P16 and P63. 
Table 4. Characteristics of patients with major discrepancies.

\begin{tabular}{|c|c|c|c|c|c|}
\hline & $\begin{array}{l}\text { Specimen } \\
\text { type }\end{array}$ & Original diagnosis & Second opinion & IHQ & Treatment alteration \\
\hline \multicolumn{6}{|c|}{ Ovarian cancer } \\
\hline 1 & Ovary & Mucinous, EOC & Krukenberg (gastric) & Yes & Surgery cancelled \\
\hline 2 & Ovary & Serous borderline & High-grade Serous EOC & Yes & Surgery modified \\
\hline 3 & Ovary & Serous borderline & Endosalpingiosis & No & Surgery modified \\
\hline 4 & Ovary & Serous EOC & Benign cystadenoma & No & Surgery modified \\
\hline 5 & Ovary & Mucinous EOC, G1 & Serous cystadenoma & No & Surgery modified \\
\hline 6 & Ovary & Immature teratoma & Mature teratoma & No & Surgery modified \\
\hline 7 & Ovary & Serous, EOC, G3 & Yolk sac tumour & Yes & Different CT \\
\hline \multicolumn{6}{|c|}{ Endometrial cancer } \\
\hline 8 & Uterus & Endometrioid, G1 & High-grade serous carcinoma & Yes & Surgical re-staging \\
\hline 9 & $D \& C$ & Endometrioid intraepithelial & High-grade serous carcinoma & Yes & Surgery modified \\
\hline 10 & Biopsy & Endometrioid, G1 & Clear cell & Yes & Surgery modified \\
\hline 11 & Biopsy & Endometrioid intraepithelial & High-grade serous carcinoma & Yes & Surgery modified \\
\hline 12 & Biopsy & Endometrioid, G1 & High-grade serous carcinoma & Yes & Surgery modified \\
\hline 13 & Biopsy & Serous, grade not described & Endometrioid, G2 & No & Surgery-CT modified \\
\hline 14 & Uterus & Undifferentiated sarcoma & Low-grade endometrial stromal sarcoma & Yes & Radiotherapy cancelled \\
\hline \multicolumn{6}{|c|}{ Cervical cancer } \\
\hline 15 & Biopsy & Adenocarcinoma & Neuroendocrine carcinoma & Yes & CT added \\
\hline 16 & Biopsy & Squamous, G2 & High-grade intraepithelial lesion & No & Surgery modified \\
\hline 17 & Biopsy & Squamous, G2 & High-grade intraepithelial lesion & No & Surgery modified \\
\hline 18 & Biopsy & Urothelial/endometrial carcinoma & Squamous, G3 & Yes & Different chemotherapy \\
\hline
\end{tabular}

Legends: EOC: epithelial ovarian cancer; CT: Chemotherapy; D\&C: dilatation and curettage; IHQ: Immunohistochemical requirement

\section{Literature review}

The literature review identified eight retrospective studies, which evaluated the level of discrepancy between the initial pathology diagnosis and the referral diagnosis after slides review. The studies were published between 1998 and 2014 and included a total of 3,463 patients with gynaecological cancer. Six studies analysed all types of gynaecological cancer, while two additional studies evaluated ovarian and vulvar cancer separately. Table 5 shows the minor discrepancy in women with endometrial cancer ranged between $6.3 \%$ and $24 \%$, while major ones between $0.6 \%$ and $13.5 \%$. The range of minor discrepancies in ovarian cancer was $3.7 \%-38 \%$ and the major discrepancy was $5 \%-9.2 \%$. Women with cervical cancer had a range of minor and major discrepancies of $2.5 \%-36 \%$ and $0.7 \%-8.3 \%$, respectively.

\section{Discussion}

This study showed a discrepancy in the pathology diagnosis between the original centre and IVO in $33.5 \%$ of patients with gynaecological cancer. Of them, $6.9 \%$ had major discrepancies and $26.6 \%$ had minor discrepancies that did not changed the patients' treatment. The distribution of the latter group was $19 \%, 27.7 \%, 9.3 \%$ and $50 \%$ of patients with endometrial, ovarian, cervical and vulvar cancer, respectively. 
Table 5. Studies reporting minor and major discrepancies in women with gynaecological cancer.

\begin{tabular}{|c|c|c|c|c|c|c|c|c|c|}
\hline \multirow[b]{2}{*}{ Author, year } & \multirow[b]{2}{*}{$\mathrm{N}$} & \multicolumn{2}{|c|}{ Endometrial cancer } & \multicolumn{2}{|c|}{ Ovarian cancer } & \multicolumn{2}{|c|}{ Cervical cancer } & \multicolumn{2}{|c|}{ Vulvar cancer } \\
\hline & & Minor & Major & Minor & Major & Minor & Major & Minor & Major \\
\hline Santoso et al. [1] & 720 & $\begin{array}{l}18 / 170 \\
(10 \%)\end{array}$ & $\begin{array}{l}1 / 170 \\
(0.6 \%)\end{array}$ & $\begin{array}{l}10 / 105 \\
(9.5 \%)\end{array}$ & $\begin{array}{l}5 / 105 \\
(5 \%)\end{array}$ & $\begin{array}{l}45 / 289 \\
(15.5 \%)\end{array}$ & $\begin{array}{l}2 / 289 \\
(0.7 \%)\end{array}$ & $\begin{array}{l}18 / 156^{*} \\
(11.5 \%)\end{array}$ & $\begin{array}{l}5 / 156^{*} \\
(3.2 \%)\end{array}$ \\
\hline Chan et al. [7] & 569 & $\begin{array}{l}34 / 242 \\
(14 \%)\end{array}$ & $\begin{array}{l}20 / 242 \\
(8.2 \%)\end{array}$ & $\begin{array}{l}9 / 54 \\
(16.6 \%)\end{array}$ & $\begin{array}{l}5 / 54 \\
(9.2 \%)\end{array}$ & $\begin{array}{l}27 / 233 \\
(11.6 \%)\end{array}$ & $\begin{array}{l}12 / 233 \\
(5.1 \%)\end{array}$ & $\begin{array}{l}2 / 35 \\
(5.7 \%)\end{array}$ & $\begin{array}{l}2 / 35 \\
(5.7 \%)\end{array}$ \\
\hline Selman et al. [6] & 295 & $\begin{array}{l}6 / 94 \\
(6.3 \%)\end{array}$ & $\begin{array}{l}7 / 94 \\
(7.4 \%)\end{array}$ & $\begin{array}{l}1 / 34 \\
(2.9 \%)\end{array}$ & $\begin{array}{l}3 / 34 \\
(8.8 \%)\end{array}$ & $\begin{array}{l}3 / 119 \\
(2.5 \%)\end{array}$ & $\begin{array}{l}1 / 119 \\
(0.8 \%)\end{array}$ & $0 / 43$ & $\begin{array}{l}3 / 43 \\
(7 \%)\end{array}$ \\
\hline Chafe et al. [8] & 599 & $\begin{array}{l}60 / 296 \\
(20 \%)\end{array}$ & $\begin{array}{l}40 / 296 \\
(13.5 \%)\end{array}$ & $\begin{array}{l}22 / 122 \\
(18 \%)\end{array}$ & $\begin{array}{l}10 / 122 \\
(8.2 \%)\end{array}$ & $\begin{array}{l}46 / 127 \\
(36 \%)\end{array}$ & $\begin{array}{l}8 / 127 \\
(6.3 \%)\end{array}$ & $\begin{array}{l}9 / 33 \\
(27.2 \%)\end{array}$ & $\begin{array}{l}2 / 33 \\
(6 \%) \\
\end{array}$ \\
\hline Khalifa et al. [3] & 351 & $\begin{array}{l}38 / 159 \\
(24 \%)\end{array}$ & $\begin{array}{l}18 / 159 \\
(11.3 \%)\end{array}$ & $\begin{array}{l}13 / 55 \\
(23.6 \%)\end{array}$ & $\begin{array}{l}4 / 55 \\
(7.2 \%)\end{array}$ & $\begin{array}{l}11 / 84 \\
(13 \%)\end{array}$ & $\begin{array}{l}7 / 84 \\
(8.3 \%)\end{array}$ & $\begin{array}{l}3 / 28 \\
(10.7 \%)\end{array}$ & $0 / 28$ \\
\hline Eskanderet al. [9] & 279 & $\begin{array}{l}11 / 100 \\
(11 \%)\end{array}$ & $\begin{array}{l}7 / 100 \\
(7 \%)\end{array}$ & $\begin{array}{l}2 / 53 \\
(3.7 \%)\end{array}$ & $\begin{array}{l}3 / 53 \\
(5.6 \%)\end{array}$ & $\begin{array}{l}5 / 86 \\
(5.8 \%)\end{array}$ & $\begin{array}{l}5 / 86 \\
(5.8 \%)\end{array}$ & $\begin{array}{l}6 / 31 \\
(19.3 \%)\end{array}$ & $\begin{array}{l}3 / 31 \\
(9.6 \%)\end{array}$ \\
\hline Kommoss et al. [10] & 454 & - & - & $\begin{array}{l}128 / 454 \\
(28 \%)\end{array}$ & $\begin{array}{l}31 / 454 \\
(7 \%)\end{array}$ & - & - & - & - \\
\hline Beugelinget al. [11] & 121 & - & - & - & - & - & - & $0 / 121$ & $\begin{array}{l}2 / 121 \\
(1.6 \%)\end{array}$ \\
\hline $\begin{array}{l}\text { Current series } \\
2018\end{array}$ & 259 & $\begin{array}{l}16 / 84 \\
(19 \%)\end{array}$ & $\begin{array}{l}7 / 84 \\
(8.3 \%)\end{array}$ & $\begin{array}{l}35 / 126 \\
(27.7 \%)\end{array}$ & $\begin{array}{l}7 / 126 \\
(5.5 \%)\end{array}$ & $\begin{array}{l}15 / 43 \\
(34.8 \%)\end{array}$ & $\begin{array}{l}4 / 43 \\
(9.3 \%)\end{array}$ & $\begin{array}{l}3 / 6 \\
(50 \%)\end{array}$ & $\begin{array}{l}0 / 6 \\
(0 \%)\end{array}$ \\
\hline
\end{tabular}

* Including 43 vaginal cancer

Observing major discrepancies between the initial and the referral pathology diagnosis in women with gynaecological cancer is considered the most important goal. Other authors have observed a major discrepancy rate ranging from $0.6 \%$ to $13 \%$, which is in range with the present study (Table 5) [1, 3, 6-11]. The definition of 'major discrepancy' varies in each study. While the great majority of those studies defined major discrepancy as a disagreement that altered the treatment [1, 3, 7, 9, 10], one study also included cases in which the prognosis was altered as well [6]. This could be one of the explanations as to why the range found is broad among the different studies previously published.

To our knowledge, this is the first study that specifically describes the pathology diagnosis discrepancy that does not alter the treatment in patients with gynaecological cancer. However, this type of disagreement, usually classified as a minor discrepancy, [1, 3, 7, 9] can also give relevant information, leading to modifications on the patient's counselling in terms of prognosis of the disease, type of follow-up, while reducing patient/family anxiety. Minor discrepancies in gynaecological cancer can include a group of pathology characteristics such as: tumour grade, histology subtype, depth of stromal invasion, as well as tumour origin. It is also important to highlight that some patients asked for a second opinion after completing the initial treatment. Thus, in some cases in the present study (patients \# 2, 3, 4, 5, 6, 13, 16, 17 of Table 4), even though a second pathology review found a major discrepancy that would have modified the initial treatment strategy, patients did not receive any treatment modification because they asked for a second opinion after receiving full treatment.

Modification in tumour grade differentiation can alter clinical management and counselling in different types of gynaecological cancers. Thus, while this information rarely modifies the management of cervical cancer, tumour grade can be important in endometrial and ovarian malignancies. Our study identified two women initially diagnosed with high-grade serous ovarian cancer, which was then downgraded to low-grade EOC. Even though this was classified as a minor discrepancy, these patients were counselled differently regarding their prognosis and the potential chemoresistance of their disease [14].

The present study also noted the minor discrepancy in the histology subtype in 23 out of 259 patients (Table 3). Given that many of these patients already arrived after the initial treatment or at relapse of the disease, the treatment was not modified. However, the patients' counselling regarding future follow-up and prognosis was significantly changed. Histology subtype is a common area of discrepancy in gynaecological cancer $[3,10]$. As in our study, other authors have found a discrepancy in serous, endometrioid or sarcoma histology in women with uterine 
cancers [3]. In addition, disagreement in histology subtype was also noted in other studies in ovarian cancer [10]. A sub-analysis of a prospectively randomised phase III study analysed 454 patients with an original diagnosis of epithelial ovarian carcinoma. All original slides were requested, and a specialised central pathology review was performed by experienced pathologists in gynaecological cancer. A total of 15 (3.3\%) patients were misdiagnosed as having invasive cancers, while histology discrepancy among EOC was noted in 128 (28.2\%) patients [10].

The current study is limited, however, by the fact that only selected slides and/or paraffin blocks were sent for revision at IVO. One interesting study compared 468 cases with selected slides with 128 cases in which all slides were available. Even though all medical conditions were included, the authors noted less disagreement in the 'selected slide group' than in the 'all slide group' (12\% versus 18\%, $p=0.03$ ) [15]. While it seems that sending all slides is better, selecting the appropriate slides to be sent is time-consuming for the original pathologists and often requires a second opinion at the original institution in order to ensure that the original diagnosis is correct. One proposed alternative is to write in the original pathology report which slides are most appropriate to confirm the diagnosis. Another matter of concern is whether some reliable slides should be retained or not at the original institution for legal purposes for a potential lawsuit in the future. This situation might be previously arranged between both institutions to return the material once the second opinion has been made at the referral institution [15].

In either setting, once a discrepancy is noted, it seems appropriate to perform a second opinion at the same referral institution [16]. In case of persistence, contacting the original pathologist to discuss the point of disagreement and to confirm the discrepancy or not is recommended [17]. This situation certainly will improve the overall quality of pathologists' performance by sharing knowledge and information and will be finally translated into a better quality of care for patients.

Another area of concern, according to histology and grading modification, would be that, although at this very moment only the use of poly ADP ribose polymerase (PARP) inhibitors is driven by both conditions, current efforts are being carried out to select emerging targeted therapies based on histology and grade, not only on tumour location.

Even though the present study has strengths, which include the first study in its nature specifically designed to describe pathology discrepancies that do not lead to modifications in the treatment in women with gynaecological cancer, our results have limitations. First, the retrospective collection of data might be associated with pathologists' misinterpretation and missed information, as well as with lost patients. Second, even though the patients' characteristics are homogeneous, the number of analysed cases might be small to reach strong results and conclusions; therefore, it should be interpreted with caution. Third, a subset of patients might not be referred to the second institution for further management or second opinion.

\section{Conclusion}

In conclusion, the incidence of minor and major discrepancies in women with gynaecological cancer was $26.6 \%$ and $6.9 \%$, respectively. The second pathology review can not only modify the treatment strategy in some cases but can also give relevant information regarding different disease prognosis, follow-up and improve patient's counselling. Therefore, a second pathology review performed by expert pathologists at referral centres should be performed in gynaecological cancer patients who ask for a second opinion.

\section{Acknowledgment}

The authors thank Isidro Machado, MD, PhD (Pathology Department, Instituto Valenciano de Oncología) for the critical review of the final manuscript.

\section{Conflict of interest}

All the authors declare that they have no competing interests.

\section{Ethical approval}

The Institutional Review Board approved the execution of the study. 


\section{Informed consent}

All patients signed informed consent to analyse the pathology samples. Specific informed consent was not required in this study.

\section{References}

1. Santoso JT, Coleman RL, and Voet RL, et al (1998) Pathology slide review in gynecologic oncology Obstet Gynecol 91(5 Pt 1) $730-734$ PMID: 9572220

2. Manion $E$, Cohen MB, and Weydert J (2008) Mandatory second opinion in surgical pathology referral material: clinical consequences of major disagreements Am J Surg Pathol 32(5) 732-737 https://doi.org/10.1097/PAS.0b013e31815a04f5 PMID: 18360282

3. Khalifa MA, Dodge J, and Covens A, et al (2003) Slide review in gynecologic oncology ensures completeness of reporting and diagnostic accuracy Gynecol Oncol 90(2) 425-430 https://doi.org/10.1016/S0090-8258(03)00323-8 PMID: 12893212

4. Program in evidence-based care (PEBC), cancer care Ontario (CCO) [https://www.cancercare.on.ca/common/pages/UserFile. aspx?fileld=311334] Date accessed: 22/7/2018

5. Tomaszewski JE, Bear HD, and Connally JA, et al (2000) Consensus conference on second opinions in diagnostic anatomic pathology. Who, what, and when Am J Clin Pathol 114(3) 329-335 https://doi.org/10.1093/ajcp/114.3.329 PMID: 10989631

6. Selman AE, Niemann TH, and Fowler JM, et al (1999) Quality assurance of second opinion pathology in gynecologic oncology Obstet Gynecol 94(2) 302-306 PMID: 10432147

7. Chan YM, Cheung AN, and Cheng DK, et al (1999) Pathology slide review in gynecologic oncology: routine or selective? Gynecol Oncol 75(2) 267-271 https://doi.org/10.1006/gyno.1999.5567 PMID: 10525384

8. Chafe S, Honore L, and Pearcey R, et al (2000) An analysis of the impact of pathology review in gynecologic cancer Int J Radiat Oncol Biol Phys 48(5) 1433-1438 https://doi.org/10.1016/S0360-3016(00)00791-4 PMID: 11121644

9. Eskander RN, Baruah J, and Nayak R, et al (2013) Outside slide review in gynecologic oncology: impact on patient care and treatment Int J Gynecol Pathol 32(3) 293-298 https://doi.org/10.1097/PGP.0b013e31826739c4 PMID: 23518913

10. Kommoss S, Pfisterer J, and Reuss A, et al (2013) Specialized pathology review in patients with ovarian cancer: results from a prospective study Int J Gynecol Cancer 23(8) 1376-1382 https://doi.org/10.1097/IGC.0b013e3182a01813 PMID: 24257551

11. Beugeling M, Ewing-Graham PC, and Mzallassi Z, et al (2014) Pathology slide review in vulvar cancer does not change patient management SRN Surg 2014385386

12. Kurman RJ, Ellenson LH, and Ronnet BM (2011) Blaustein's Pathology of the Female Genital Tract 6th edn

13. Kurman RJ, Carcangiu ML, and Simon Herrington C, et al (2014) WHO Classification of Tumours of Female Reproductive Organs 4th edn (Lyon: International Agency for Research on Cancer (IARC))

14. Gershenson DM (2016) Low-grade serous carcinoma of the ovary or peritoneum Ann Oncol 27(1) i45-i49 https://doi.org/10.1093/ annonc/mdw085 PMID: 27141071

15. Renshaw MA, Renshaw AA, and Gould EW (2009) Should pathologists send all or only selected slides for patient-requested interlaboratory second opinion? Am J Clin Pathol 132(5) 763-766 https://doi.org/10.1309/AJCP55VZZLQEHPPS PMID: 19846819

16. Abt AB, Abt L, and Olt GJ (1995) The effect of interinstitution anatomic pathology consultation on patient care Arch Pathol Lab Med 119 514-517 PMID: 7605166

17. Renshaw AA and Gould EW (2006) Measuring the value of review of pathology material by a second pathologist Am J Clin Pathol 125 737-739 https://doi.org/10.1309/6AORAX9KCR8VWCG4 PMID: 16707375 